\title{
Does Low-Molecular-Weight Heparin Influence the Antimyeloma Effects of Thalidomide? A Retrospective Analysis of Data from the GIMEMA, Nordic and Turkish Myeloma Study Groups
}

\author{
Meral Beksac $^{a}$ Anders Waage $^{b}$ Sara Bringhen ${ }^{c}$ Sigurdur Y. Kristinsson ${ }^{d}$ \\ Gülsan Türköz Sucak ${ }^{e}$ Peter Gimsing ${ }^{f}$ Giulia Lupparellic ${ }^{c}$ Tulin Fıratlı-Tuğlular ${ }^{g}$ \\ Gunnar Juliusson $^{\text {h }}$ Ingemar Turesson ${ }^{\text {i }}$ Antonio Palumbo ${ }^{c}$ \\ a Department of Hematology, Faculty of Medicine, Ankara University, Ankara, Turkey; ${ }^{b}$ Department of Hematology, St.

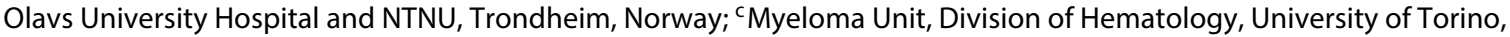 \\ Azienda Ospedaliero Universitaria S. Giovanni Battista, Torino, Italy; ${ }^{\mathrm{d}}$ Department of Hematology, Karolinska University

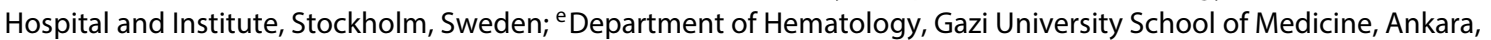 \\ Turkey; ${ }^{\mathrm{f}}$ Department of Hematology, University of Copenhagen, Copenhagen, Denmark; ${ }^{9}$ Department of Hematology,

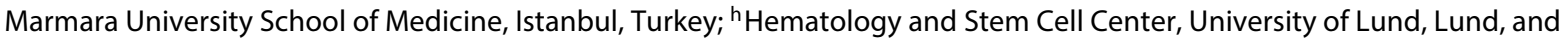 \\ 'Department of Hematology and Coagulation Disorders, Skane University Hospital, Malmö, Sweden
}

\section{Key Words}

Anticoagulation · Heparin · Low-molecular-weight heparin · Multiple myeloma $\cdot$ Thalidomide

\footnotetext{
Abstract

Background/Aim: Low-molecular-weight heparin (LMWH) has been shown to prolong survival among patients with solid tumors, but its role among myeloma patients is unknown. Patients: Data from the GIMEMA (Gruppo Italiano Malattie Ematologiche dell'Adulto), Nordic and Turkish myeloma study groups comparing melphalan and prednisolone with (MPT, n: 404) or without thalidomide (MP, n: 393) are analyzed for effects of LMWH. Forty percent (159/394) of the patients on MPT and 7.4\% (29/390) in the MP arm received LMWH. Results: Thalidomide improved response and progression-free survival (PFS). Regardless of thalidomide treatment, response rate was higher among those receiving LMWH vs. none vs. other anticoagulants ( 58.1 vs. 44.9 vs. $50.4 \%, p=0.01$ ). PFS was significantly longer (median 32 vs.
}

21 and 17 vs. 17 months, $p=0.004$ ) only among international scoring system (ISS) I patients receiving MPT \pm LMWH vs. $M P \pm L M W H$. The group of MPT patients who also received LMWH had a better OS compared to those who did not [45 months, 95\% confidence interval (Cl) 27.7-62.3, vs. 32 months, 95\% Cl 26.1-37.9; $\mathrm{p}=0.034]$. When multivariate analysis was repeated in subgroups, thalidomide was no longer a significant factor (response, PFS) among those receiving LMWH. Conclusion: Addition of LMWH to MPT, in particular in patients with low ISS, suggests additive effects, but the results are limited by the retrospective design of our study.

(c) 2015 S. Karger AG, Basel

\section{Introduction}

A multidisciplinary approach is essential to successfully fight cancer in general. Multiple myeloma treatment includes a wide spectrum of approaches aiming to control

\section{KARGER 125}

(c) 2015 S. Karger AG, Base

$0001-5792 / 15 / 1334-0372 \$ 39.50 / 0$ 
Table 1. Distribution of patients across the GIMEMA, Nordic (NMSG12) and Turkish Myeloma Study Groups (TMSG) according to anticoagulation and thalidomide use

\begin{tabular}{|c|c|c|c|c|c|c|c|c|}
\hline & \multicolumn{2}{|c|}{ GIMEMA } & \multicolumn{2}{|c|}{ NMSG12 } & \multicolumn{2}{|c|}{ TMSG } & \multicolumn{2}{|c|}{ Total } \\
\hline LMWH as prophylaxis & 0 & 95 & 12 & 10 & 1 & 18 & 13 & 123 \\
\hline LMWH as treatment & 2 & 18 & 11 & 13 & 3 & 5 & 16 & 36 \\
\hline Total & 164 & 167 & 169 & 169 & 57 & 58 & 390 & 394 \\
\hline
\end{tabular}

myeloma cell growth. Prevention or treatment of damage to the skeleton, bone marrow, neurons, kidneys and the coagulation-fibrinolytic system are essential elements of therapy $[1,2]$. Identification of multiple targets has led to an expansion in the number of drugs utilized. Immunomodulatory drugs have been shown to improve response rates and prolong survival [1,3-9]. Venous thromboembolism (VTE) occurs in 5-25\% of patients treated with immunomodulatory drugs and has led to prophylactic use of low-molecular-weight heparins (LMWH) [2]. Heparin is not only an anticoagulant, it also has additional anti-inflammatory and antimetastatic effects [10-12]. Heparin exerts these activities through adhesion molecules via the inhibition of procoagulant molecules, such as heparanase and protease-activated receptor (PAR-1 and/or CD24), which are expressed by cancer cells [2, 1016]. Heparin is a potent inhibitor of heparanase. However, heparanase may neutralize heparin activity [13]. Myeloma cells cause an increase in heparanase expression leading to protease, osteoclastogenesis activation and osteoblastogenesis inhibition $[14,15]$. Furthermore, heparanase-mediated syndecan-1 (CD138) shedding has been claimed to be responsible for myeloma progression $[15,16]$. The interactions of heparanoids with the microenvironment during cancer dissemination are a continuously evolving field [12].

Based on these data, we hypothesized that among patients being prescribed melphalan combined with prednisolone (MP)/MP with thalidomide (MPT) and LMWH, in addition to the well-known anticoagulant effects of LMWH, antimyeloma activity may also be possible. To analyze response, progression-free survival (PFS) and overall survival (OS), we pooled study data on VTE and anticoagulation from three trials which compared MP versus MPT.

Does LMWH Have an Antimyeloma Effect?

\section{Patients and Methods}

Individual data from 797 patients who were randomized to MP $(n=393)$ or MPT $(n=404)$ and published by the GIMEMA (Gruppo Italiano Malattie Ematologiche dell'Adulto), Nordic and Turkish Myeloma Study Groups were included in this retrospective analysis $[3,7,8]$. The other three European trials which compared MPT to MP were not eligible for this analysis because detailed data on LMWH use were not recorded [4-6]. Myeloma treatment and anticoagulation is summarized in table 1. Except for the Nordic trial and the early phase of the GIMEMA trial, anticoagulation or aspirin was given routinely to MPT patients. Patients who received LMWH as routine prophylaxis or following a thrombotic event were assigned to the LMWH group. Likewise, patients receiving other anticoagulants or none were grouped together or separately (tables 1-7; fig. 1,2) accordingly. Response equal to or more than a partial response was included in the response analysis. The impact of the treatment arm (MPT vs. MP), use of anticoagulation (LMWH vs. others vs. none), use of LMWH (yes vs. no), prognostic factors [gender, age, international scoring system (ISS) and creatinine] were evaluated for effects on response, PFS and OS.

\section{Statistical Analyses}

Descriptive statistics were presented as means, standard deviations, medians, minimum/maximum for quantitative variables, and as numbers and percentages for categorical variables. In categorical comparisons, the $\chi^{2}$ test was used for independent groups and the Monte Carlo simulation for multigroup comparisons which did not meet the $\chi^{2}$ requirement. Fisher's exact test was used in paired group comparisons. In numerical comparisons, when normal distribution was not provided, the Mann-Whitney $\mathrm{U}$ test was used for paired independent groups and the Kruskal-Wallis test for multiple independent groups. Subgroup analysis of multigroup comparisons were performed by Mann-Whitney U test with Bonferroni correction. Logistic regression analysis was used to determine risk factors for response. Survival analysis was performed by Kaplan-Meier analysis. Cox regression analysis was used in the determination of risk factors affecting survival. A backward stepwise model was also used to determine independent risk factors. The statistical level of significance was set at $\mathrm{p}<0.05$. All statistical analyses were performed using SPSS 15.0 for Windows.

Acta Haematol 2015;133:372-380 
Table 2. Comparison of clinical characteristics and outcomes between groups according to treatment: MP $\pm \mathrm{LMWH}$ and MPT $\pm \mathrm{LMWH}$

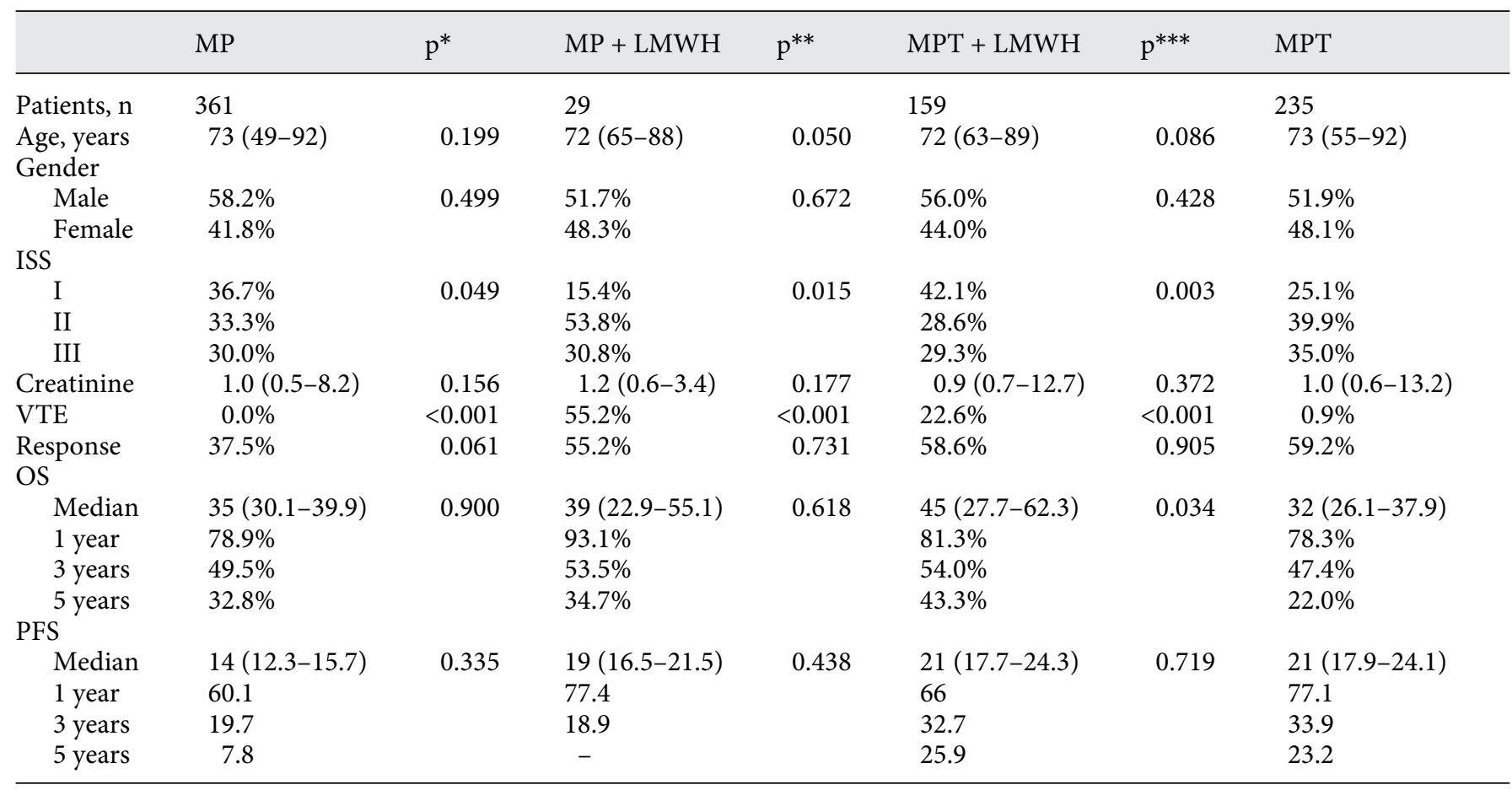

Patients treated with either no anticoagulant or anticoagulants other than heparin are included in the MP or MPT groups.

${ }^{*} \mathrm{p}=\mathrm{MP}$ vs. MP + LMWH, ${ }^{* *} \mathrm{p}=\mathrm{MP}+\mathrm{LMWH}$ vs. MPT $+\mathrm{LMWH},{ }^{* * *} \mathrm{p}=\mathrm{MPT}+\mathrm{LMWH}$ vs. MPT.

Table 3. Effect of thalidomide anticoagulation, on response, relapse (after a median follow-up of 13 months) and survival (after a median follow-up of 24 months) rates

\begin{tabular}{|c|c|c|c|c|c|c|}
\hline & $\geq$ Partial response & $\mathrm{p}$ & Relapse & $\mathrm{p}$ & Survival & $\mathrm{p}$ \\
\hline Treatment & $381 / 776$ & & $325 / 797$ & & $407 / 796$ & \\
\hline MP vs. MPT & 38.8 vs. $59.0 \%$ & $<0.001$ & 65.1 vs. $53.5 \%$ & 0.001 & 52.7 vs. $49.6 \%$ & n.s. \\
\hline None vs. LMWH vs. other & 44.9 vs. 58.1 vs. $50.4 \%$ & 0.010 & 61.2 vs. 60.6 vs. $51.5 \%$ & n.s. & 51.7 vs. 53.7 vs. $46.5 \%$ & n.s. \\
\hline
\end{tabular}

\section{Results}

A total of 797 multiple myeloma patients were included in the three clinical trials (tables 1,2). Altogether, 188 patients were treated with LMWH (29 in the MP arm and 159 in the MPT arm). The reason for LMWH administration was prophylaxis in 136 patients (13 in the MP arm and 123 in the MPT arm) and treatment in 52 patients (16 in the MP arm and 36 in the MPT arm). The indications for treatment included VTE, arrhythmia and other cardiac disease. VTE were not reported among the MP patients. One hundred and thirty patients received anticoagulation other than LMWH (59 in the MP arm and 71 in the MPT arm). In the MP group, ISS stage I was more common among patients not treated with LMWH (36.7 vs. $15.4 \% ; \mathrm{p}=0.049$ ) while in the MPT arm ISS stage I was more common among patients treated with LMWH (42.1 vs. $25.1 \% ; \mathrm{p}=0.003$; table 2 ). As expected, there were more VTEs in patients given LMWH since patients treated for VTE were included in this group.

Effects of thalidomide and anticoagulation on response, relapse and survival among all patients pooled together are summarized in table 3. Median follow-up times were 13 (relapse rate) and 24 (survival rate) months. In this study cohort, thalidomide improved response and relapse rates without any significant effect on OS. LMWH 
Table 4. Comparison of PFS rate and duration between treatment groups according to ISS

\begin{tabular}{|c|c|c|c|c|c|}
\hline & $\begin{array}{l}\text { MP } \\
(n=361)\end{array}$ & $\begin{array}{l}\text { MP + LMWH } \\
(\mathrm{n}=29)\end{array}$ & $\begin{array}{l}\text { MPT + LMWH } \\
(\mathrm{n}=159)\end{array}$ & $\begin{array}{l}\text { MPT } \\
(n=235)\end{array}$ & $\mathrm{p}^{1}$ \\
\hline \multicolumn{6}{|l|}{ Overall } \\
\hline Median & $14(12.3-15.7)^{*}$ & $19(16.5-21.5)$ & $21(17.7-24.3)^{*}$ & $21(17.9-24.1)$ & \multirow[t]{3}{*}{$<0.001$} \\
\hline 1 year & 60.1 & 77.4 & 66 & 77.1 & \\
\hline 3 years & 19.7 & 18.9 & 32.7 & 33.9 & \\
\hline Median & $17(13.5-20.5)^{* *}$ & $17(12.2-21.8)$ & $32(23.8-40.2)^{* *}$ & $21(12.9-29.1)$ & \multirow[t]{4}{*}{0.004} \\
\hline 1 year & 65.9 & 100 & 80.4 & 76.3 & \\
\hline 3 years & 22.7 & 0.0 & 41 & 35.9 & \\
\hline 5 years & 7.8 & - & 41 & 31.4 & \\
\hline \multicolumn{6}{|l|}{ ISS II } \\
\hline Median & $14(11.3-16.7)$ & $19(12.9-25.1)$ & $21(13.2-28.8)$ & $24(16.2-31.8)$ & n.s. \\
\hline Median & $12(10.3-13.7)$ & $27(11.7-42.3)$ & $12(3.3-20.7)$ & $18(14.5-21.5)$ & \multirow[t]{4}{*}{ n.s. } \\
\hline 1 year & 55.5 & 68.6 & 51.5 & 68.3 & \\
\hline 3 years & 10.6 & 25.7 & 22.3 & 34.5 & \\
\hline 5 years & 10.6 & - & 0.0 & 20.7 & \\
\hline
\end{tabular}

Table 5. Comparison of OS results (months) according to treatment arm (MPT vs. MP), use of LMWH and ISS

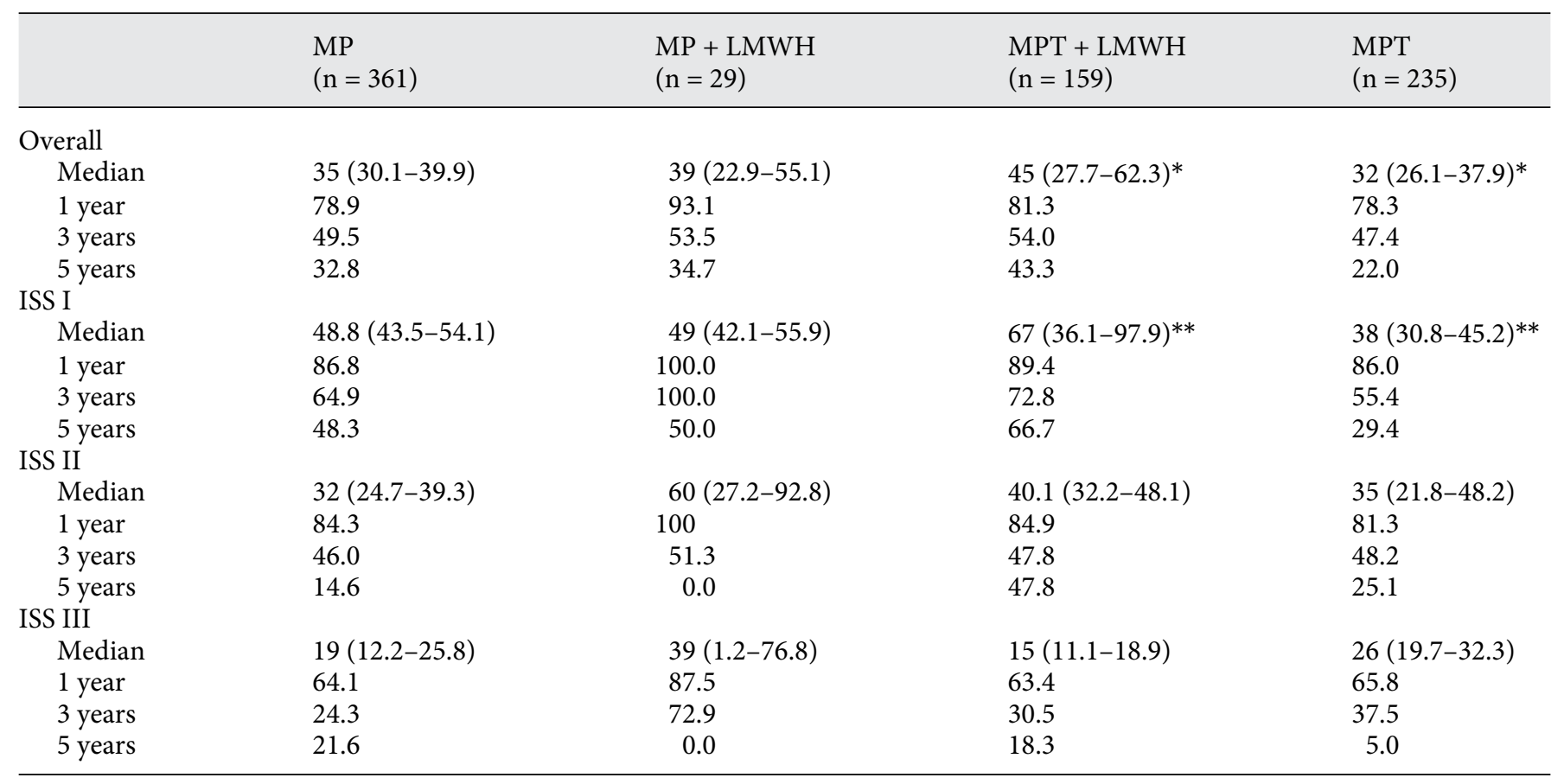

There were no significant differences of MP vs. MP + LMWH vs. MPT vs. MPT + LMWH.

${ }^{*} \mathrm{p}=0.034,{ }^{* *} \mathrm{p}=0.016, \mathrm{MPT}+\mathrm{LMWH}$ vs. MPT. 
Table 6. Results of univariate analysis on the impact of age, ISS, treatment arm (MPT vs. MP) and anticoagulation (none vs. LMWH vs. other anticoagulants) on response, PFS and OS

\begin{tabular}{|c|c|c|c|c|c|c|c|c|c|}
\hline & \multicolumn{3}{|c|}{ Response } & \multicolumn{3}{|l|}{ PFS } & \multicolumn{3}{|l|}{ OS } \\
\hline MPT & 2.264 & $1.699-3.018$ & $<0.001$ & 0.656 & $0.547-0.788$ & $<0.001$ & 1.060 & $0.869-1.294$ & n.s. \\
\hline Anticoagulation & & & & & & & & & \\
\hline None & & & 0.010 & & & n.s. & & & n.s. \\
\hline \multicolumn{10}{|l|}{ Age group } \\
\hline$<65$ years & & & n.s. & & & n.s. & & & 0.001 \\
\hline 65-70 years & 1.826 & $0.732-4.556$ & n.s. & 0.828 & $0.488-1.405$ & n.s. & 1.001 & $0.525-1.908$ & n.s. \\
\hline $71-75$ years & 1.692 & $0.677-4.227$ & n.s. & 0.746 & $0.439-1.268$ & n.s. & 0.994 & $0.521-1.898$ & n.s. \\
\hline $76-80$ years & 1.449 & $0.569-3.69$ & n.s. & 0.754 & $0.435-1.306$ & n.s. & 1.336 & $0.692-2.577$ & n.s. \\
\hline$>80$ years & 1.055 & $0.399-2.791$ & n.s. & 0.754 & $0.423-1.343$ & n.s. & 1.836 & $0.940-3.585$ & n.s. \\
\hline
\end{tabular}

seems to improve response rates without a significant effect on relapse rate or OS. PFS was significantly better among patients treated with thalidomide and/or LMWH compared to patients not receiving any of these drugs ( $\mathrm{p}<0.001$; fig. 1) As seen in figure 2, OS was not significantly influenced by thalidomide or LMWH. Tables 4 (PFS) and 5 (OS) summarize the effects of thalidomide according to ISS. When LMWH was added to MP there was a trend to a higher response rate (55.2 vs. $37.5 \%$; $\mathrm{p}=$ 0.061 ) but no significant effect on PFS (median 19 vs. 14 months; $\mathrm{p}=0.335$ ) or OS (median 39 vs. 35 months; $\mathrm{p}=$ 0.900 ; tables $2,4,5)$. In subgroup analyses of the MP patients, there was a trend to prolongation of both PFS and OS in ISS stages II and III but not in ISS stage I in patients receiving LMWH (tables 4, 5). When LMWH was added to MPT, there was a significant improvement in OS (median 45 vs. 32 months; $\mathrm{p}=0.034$; tables $2,4,5$ ) but no significant effect on response rate or PFS. In subgroup analysis of the MPT patients, PFS (32 vs. 21 months; $p=0.004$ ) was significantly longer among patients receiving LMWH in ISS stage I only (tables 4, 5). Regardless of LMWH, addition of thalidomide to MP significantly improved PFS from a median of 14 to 21 months overall ( $p<0.001$ ) and in all ISS stages (table 4). In the whole study population, patients receiving LMWH as treatment had a higher response rate than those receiving LMWH as prophylaxis ( 72.5 vs. $52.6 \%, p=0.014$ ), but this did not translate into improved PFS or OS. When MP was combined with both thalidomide and LMWH, OS improved significantly (45 vs. 32 months, $\mathrm{p}=0.034$ ) especially among patients in ISS stage I ( 67 vs. 38 months, $\mathrm{p}=0.016$; table 5 ).

In univariate analysis, use of thalidomide (MPT), use of anticoagulation (LMWH) and ISS I were significantly associated with better response and PFS. Lower ISS ( $\mathrm{p}<$ $0.001)$ as well as age younger than 65 years $(\mathrm{p}=0.001)$ were associated with improved OS (table 6). When univariate analysis was repeated within the MPT group, LMWH was found to have a significant impact on OS (OR $=0.720,95 \%$ CI: $0.526-0.985, \mathrm{p}=0.04)$. In a similar analysis within the MP group, LMWH tended to affect response $(\mathrm{OR}=1.961$, 95\% CI: $0.909-4.229, \mathrm{p}=0.086$ ) but not OS or PFS.

Using logistic regression analysis among all patients (data not shown), only age and ISS were significantly associated with OS. When the population consisted of those not receiving anticoagulation, the treatment arm (MPT) appeared to have an independent association with response and PFS or OS (table 7). If multivariate analysis was limited to patients receiving LMWH, the only significant independent predictor of OS and PFS was ISS (table 7).

\section{Discussion}

The interaction between cancer cells and coagulation has been known for many years $[2,12,20,21]$. While cancer cells trigger coagulation and cause an increased inci- 
Table 7. Results of subgroup multivariate analysis of prognostic factors (age, ISS and treatment with thalidomide) on response, PFS and OS among those receiving no anticoagulation or LWMH or others

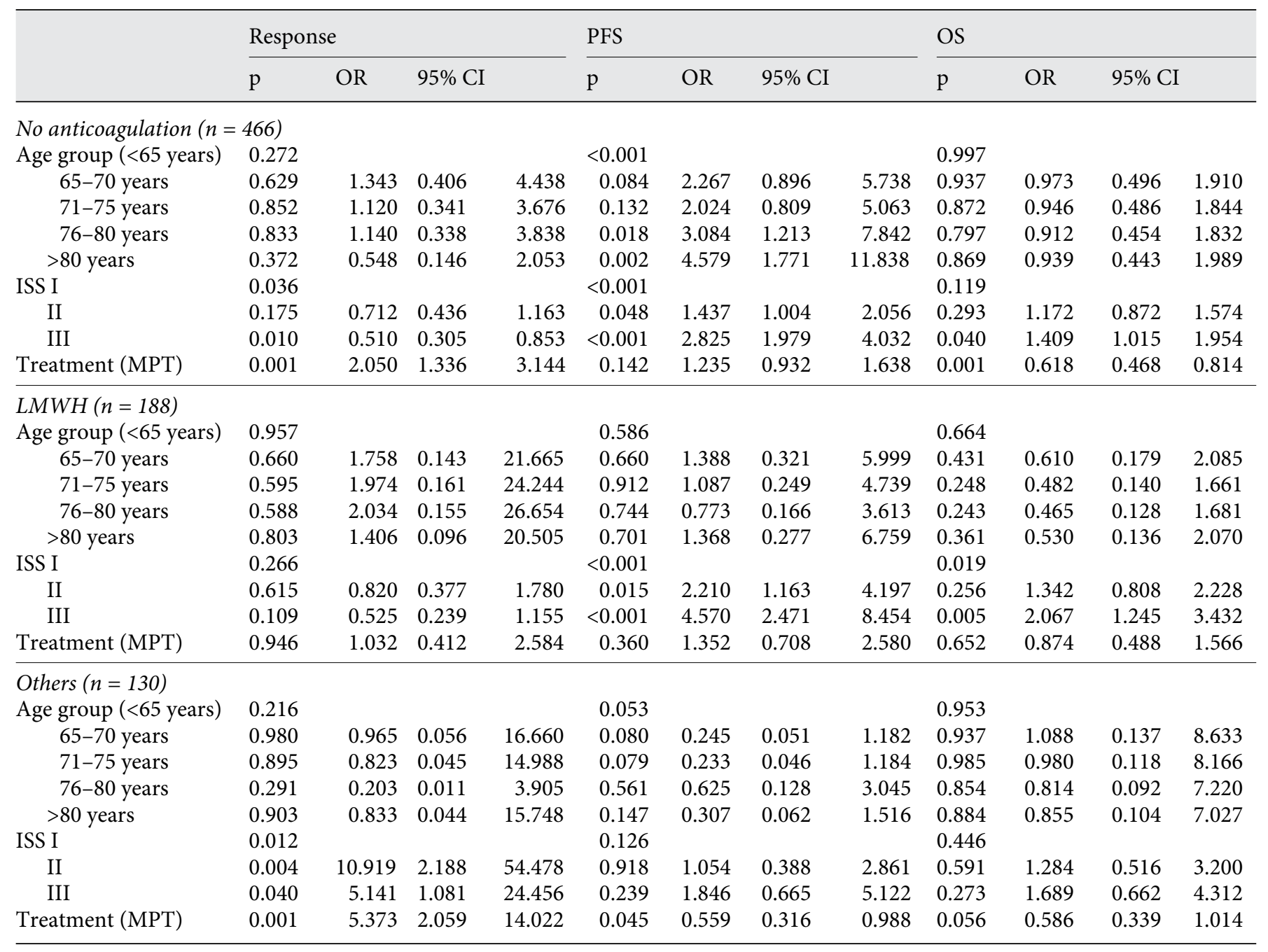

dence of VTE, cancer progression is facilitated by blood coagulation. During the last decade, studies (mainly on lung cancer) have shown a survival benefit among patients on LMWH, particularly in those with a good prognosis [21-24]. It has been claimed that even short courses of treatment may be sufficient to achieve these effects [21]. LMWH exert their activities through antithrombin and membrane-located receptors, such as protease-activated receptors $[12,13]$. Using a combination of array comparative genomic hybridization and gene expression profiles, the University of Arkansas Group discovered PAR1 [coagulation factor II (thrombin) receptor or F2R; 5q13.3] expression to be strongly correlated with gains in chromosome 5, a consistent feature of the hyperploid molecular subtype of multiple myeloma [14, 17-19].
The antimyeloma effects of thalidomide derive from anticytokine and anti-angiogenic properties. Thalidomide shares a thrombogenic potential with myeloma and thus necessitates frequent use of anticoagulation. Accumulating evidence suggesting anticancer and antimyeloma activities of heparin arising from the interaction between heparins and matrix-related proteins has led to the analysis performed in this study.

Data from three randomized clinical trials comparing MPT with MP were used in this retrospective analysis, which is the first to investigate the role of LMWH in this setting. Previous results indicate antimyeloma effects of LMWH and support our hypothesis that addition of LMWH compared to no anticoagulation or other anticoagulants significantly improved response rates, resulted 


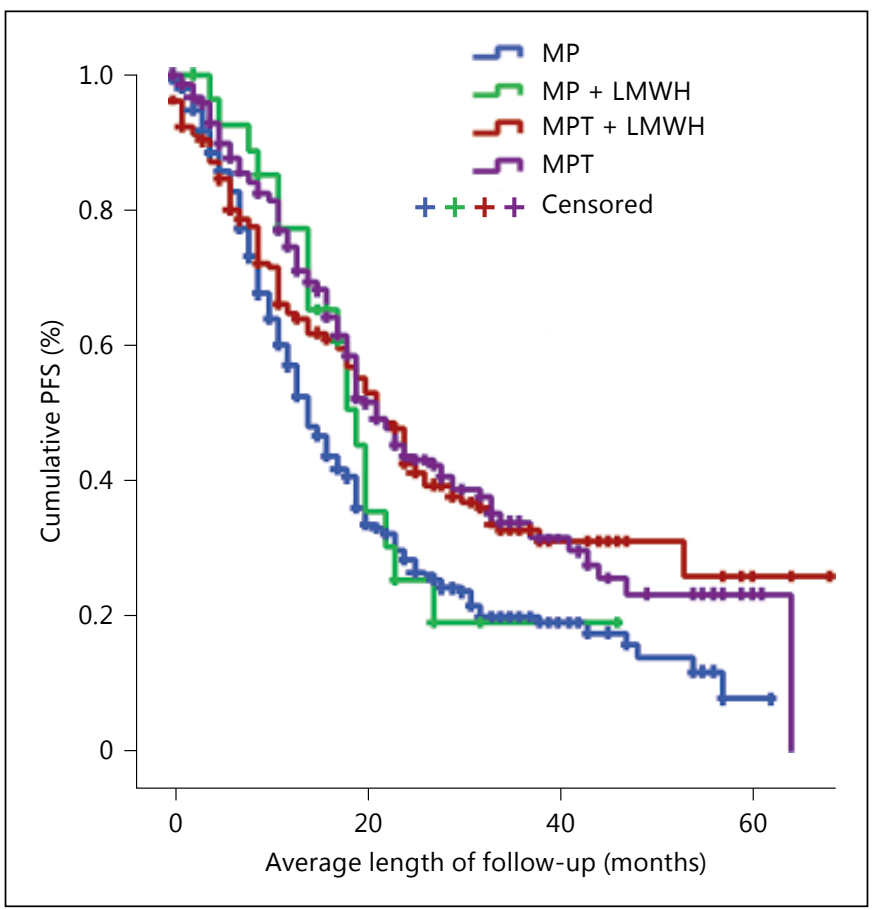

Fig. 1. $\mathrm{PFS}$ of all treatment groups (MP vs. $\mathrm{MP}+\mathrm{LMWH}$ vs. MPT vs. $\mathrm{MPT}+\mathrm{LMWH}) . \mathrm{n}=784, \mathrm{p}<0.001$.

in a decreased relapse rate (all patients) and improved OS (MPT patients). The best survival was observed when both thalidomide and LMWH were given, with a 5-year survival of $43.3 \%$ compared to $32.8 \%$ among those who did not receive any of these drugs. When the MP and MPT groups were analyzed separately, addition of LMWH significantly improved OS in the MPT group only, extending median OS from 32 to 45 months $(\mathrm{p}=0.034$ ). Subgroup analysis of the MPT patients indicated that the beneficial effect of LMWH treatment was more pronounced in low-risk patients with a significant prolongation of PFS ( $p=0.004)$ and a trend to improvement of OS in ISS I. Furthermore, in Kaplan-Meier analysis, thalidomide and LMWH were found to improve OS ( $\mathrm{p}<0.001)$.

A larger proportion of patients in the MPT group received LMWH compared to the MP group, and the indication was prophylaxis in the majority of patients, while in the MP group the indication for LMWH was equally distributed between prophylaxis and treatment. A comparison of the LMWH indication, treatment versus prophylaxis, revealed a response advantage in favor of treatment but did not produce a significant effect on PFS or OS. Thrombosis has been reported to have adverse effects on survival of patients with multiple myeloma [17]. We cannot exclude that the beneficial effect

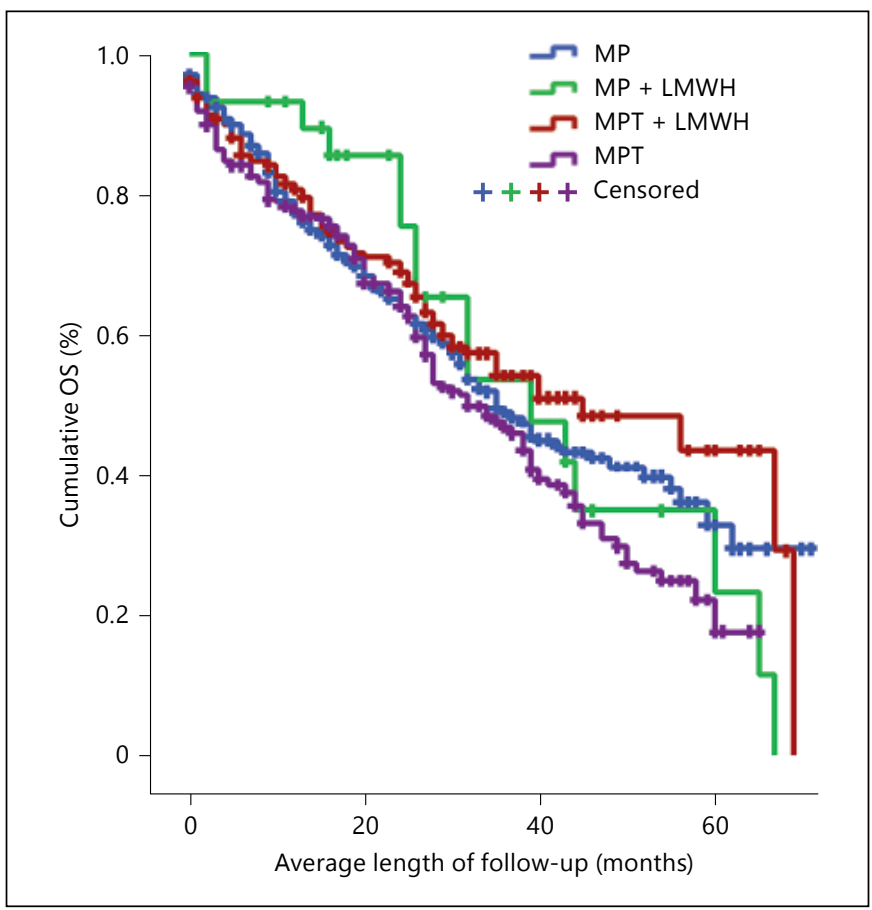

Fig. 2. OS of all treatment groups (MP vs. MP + LMWH vs. MPT vs. $\mathrm{MPT}+\mathrm{LMWH}) . \mathrm{n}=783, \mathrm{p}<0.174$.

of LMWH on OS that we have observed to some extent may be due to the prevention of VTE-related deaths. Unfortunately, we have not been able to study causes of death in detail.

Long-term results from the thalidomide studies imply that patients with a good prognosis benefit most from thalidomide. In the MRC Myeloma IX trial, the authors concluded that patients possessing good cytogenetic risk with/without ploidy benefit the most from thalidomide maintenance $[25,26]$, which is in accordance with the beneficial effects of LMWH found especially in low ISS patients in our study. There seems to be a similarity between biological features of patients who improve their outcome with thalidomide and LMWH.

Conversely, heparin may exert effects through syndecan-1 (CD138), which is highly expressed on myeloma cells and is a proteoglycan containing attachment sites for heparan sulfate [16]. Heparanase, which was shown to be highly expressed by myeloma cells, may cause syndecan-1 shedding and lead to tumor proliferation as well as dissemination. As heparin and heparanase seem to antagonize each other, heparin may mediate a beneficial effect. However, soluble heparin, mainly the unfractionated one, has been shown to displace hepatocyte growth factor from sites such as marrow into the 
circulation in normal subjects [24]. Thus, there is also a potential that heparin may induce hepatocyte growth factor-mediated myeloma proliferation [27].

In conclusion, we were able to report, for the first time, better response rates (MP and MPT combined) and prolongation of OS (MPT patients) among patients receiving LMWH. Furthermore, we were able to show that the benefits of thalidomide regarding significant and independent responses and PFS are limited to patients who are not receiving LMWH or other antithrombotic agents. Since significant PFS and OS benefits of LMWH were mostly observed among ISS I patients, the prognostic features of patients who benefit from both thalidomide and LMWH may be similar. However, our results, which are based on retrospective analyses, need to be interpreted cautiously. The lack of prospective trials prevents us from unveiling heparin-mediated interactions among myeloma patients receiving LMWH.

\section{Acknowledgment}

Statistical analyses were supported by a research grant from the Turkish Academy of Sciences.

\section{Disclosure Statement}

The authors have nothing to disclose.

\section{References}

1 Beksaç M, Delforge M, Richardson P: The evolving treatment paradigm of multiple myeloma: from past to present and future (Sürekli gelişmekte olan bir tedavi yaklaşımı: Multipl miyeloma tedavisinin geçmişi, bugünü ve geleceği). Turk J Hematol 2008;25: 60-68.

2 Palumbo A, Rajkumar SV, Dimopoulos MA, Richardson PG, San Miguel J, Barlogie B, Harousseau J, Zonder JA, Cavo $M$, Zangari $M$, Attal M, Belch A, Knop S, Joshua D, Sezer O, Ludwig H, Vesole D, Bladé J, Kyle R, Westin J, Weber D, Bringhen S, Niesvizky R, Waage A, von Lilienfeld-Toal M, Lonial S, Morgan GJ, Orlowski RZ, Shimizu K, Anderson KC, Boccadoro M, Durie BG, Sonneveld P, Hussein MA; International Myeloma Working Group: Prevention of thalidomide- and lenalidomide-associated thrombosis in myeloma. Leukemia 2008;22:414-423.

3 Palumbo A, Bringhen S, Caravita T, Merla E, Capparella V, Callea V, Cangialosi C, Grasso M, Rossini F, Galli M, Catalano L, Zamagni E, Petrucci MT, De Stefano V, Ceccarelli M, Ambrosini MT, Avonto I, Falco P, Ciccone G, Liberati AM, Musto P, Boccadoro M; Italian Multiple Myeloma Network, GIMEMA: Oral melphalan and prednisone chemotherapy plus thalidomide compared with melphalan and prednisone alone in elderly patients with multiple myeloma: randomised controlled trial. Lancet 2006;367:825-831.

4 Facon T, Mary JY, Hulin C, Benboubker L, Attal M, Pegourie B, Renaud M, Harousseau JL, Guillerm G, Chaleteix C, Dib M, Voillat L, Maisonneuve H, Troncy J, Dorvaux V, Monconduit M, Martin C, Casassus P, Jaubert J, Jardel H, Doyen C, Kolb B, Anglaret B, Grosbois B, Yakoub-Agha I, Mathiot C, Avet-Loiseau H; Intergroupe Francophone du Myélome: Melphalan and prednisone plus thalidomide versus melphalan and prednisone alone or reduced-intensity autologous stem cell transplantation in elderly patients with multiple myeloma (IFM 99-06): a randomised trial. Lancet 2007;370:1209-1218.

5 Hulin C, Facon T, Rodon P, Pegourie B, Benboubker L, Doyen C, Dib M, Guillerm G, Salles B, Eschard JP, Lenain P, Casassus P, Azaïs I, Decaux O, Garderet L, Mathiot C, Fontan J, Lafon I, Virion JM, Moreau P: Efficacy of melphalan and prednisone plus thalidomide in patients older than 75 years with newly diagnosed multiple myeloma: IFM 01/01 trial. J Clin Oncol 2009;27:36643670.

6 Wijermans P, Schaafsma M, Termorshuizen F, Ammerlaan R, Wittebol S, Sinnige $H$, Zweegman S, van Marwijk Kooy M, van der Griend R, Lokhorst H, Sonneveld P; DutchBelgium Cooperative Group HOVON: Phase III study of the value of thalidomide added to melphalan plus prednisone in elderly patients with newly diagnosed multiple myeloma: the HOVON 49 Study. J Clin Oncol 2010;28: 3160-3166.

7 Waage A, Gimsing P, Fayers P, Abildgaard N, Ahlberg L, Björkstrand B, Carlson K, Dahl IM, Forsberg K, Gulbrandsen N, Haukås E, Hjertner O, Hjorth M, Karlsson T, Knudsen LM, Nielsen JL, Linder O, Mellqvist UH, Nesthus I, Rolke J, Strandberg M, Sørbø JH, Wisløff F, Juliusson G, Turesson I; Nordic Myeloma Study Group: Melphalan and prednisone plus thalidomide or placebo in elderly patients with multiple myeloma. Blood 2010; 116:1405-1412.

8 Beksac M, Haznedar R, Firatli-Tuğlular T, Ozdogu H, Aydogdu I, Konuk N, Sucak G, Kaygusuz I, Karakus S, Kaya E, Ali R, Gulbas Z, Ozet G, Goker H, Undar L: Addition of thalidomide to oral melphalan/prednisone in patients with multiple myeloma not eligible for transplantation: results of a randomized trial from the Turkish Myeloma Study Group. Eur J Haematol 2011;86:16-22.

9 Fayers PM, Palumbo A, Hulin C, Waage A, Wijermans P, Beksaç M, Bringhen S, Mary JY, Gimsing P, Termorshuizen F, Haznedar R, Caravita T, Moreau P, Turesson I, Musto P, Benboubker L, Schaafsma M, Sonneveld P, Facon T; Nordic Myeloma Study Group; Italian Multiple Myeloma Network; Turkish Myeloma Study Group; Hemato-Oncologie voor Volwassenen Nederland; Intergroupe Francophone du Myélome; European Myeloma Network: Thalidomide for previously untreated elderly patients with multiple myeloma: meta-analysis of 1685 individual patient data from 6 randomized clinical trials. Blood 2011;118:1239-1247.

10 Ludwig RJ, Boehme B, Podda M, Henschler R, Jager E, Tandi C, Boehncke WH, Zollner TM, Kaufmann R, Gille J: Endothelial P selectin as a target of heparin action in experimental melanoma lung metastasis. Cancer Res 2004; 64:2743-2750.

11 Nelson RM, Cecconi O, Roberts WG, Aruffo A, Linhardt RJ, Bevilacqua MP: Heparin oligosaccharides bind $\mathrm{L}$ - and $\mathrm{P}$-selectin and inhibit acute inflammation. Blood 1993;82: 3253-3258.

12 Nadir Y, Brenner B: Heparanase coagulation and cancer progression. Best Pract Res Clin Haematol 2009;22:85-92.

13 Nasser NJ, Sarig G, Brenner B, Nevo E, Goldshmidt O, Zcharia E, Li JP, Vlodavsky I: Heparanase neutralizes the anticoagulation properties of heparin and low-molecularweight heparin. J Thromb Haemost 2006;4: 560-565.

14 Ruan J, Trotter TN, Nan L, Luo R, Javed A, Sanderson RD, Suva LJ, Yang Y: Heparanase inhibits osteoblastogenesis and shifts bone marrow progenitor cell fate in myeloma bone disease. Bone 2013;57:10-17. 
15 Purushothaman A, Chen L, Yang Y, Sanderson RD: Heparanase stimulation of protease expression implicates it as a master regulator of the aggressive tumor phenotype in myeloma. J Biol Chem 2008;283:32628-32636.

16 Yang Y, Macleod V, Miao HQ, Theus A, Zhan F, Shaughnessy JD Jr, Sawyer J, Li JP, Zcharia E, Vlodavsky I, Sanderson RD: Heparanase enhances syndecan-1 shedding: a novel mechanism for stimulation of tumor growth and metastasis. J Biol Chem 2007;282:1332613333.

17 Tian E, Usmani S, Zhou Y, Barlogie B, Shaughnessy JD Jr: Thrombin-induced PARI signaling pathway modulates $B$-catenin in the transformation of symptomatic myeloma cells into the quiescent phenotype. Blood 2011;118:3932a.

18 Kahn ML, Hammes SR, Botka C, Coughlin SR: Gene and locus structure and chromosomal localization of the protease-activated receptor gene family. J Biol Chem 1998;36: 23290-23296.

19 Avet-Loiseau H, Li C, Magrangeas F, Gouraud W, Gouraud W, Charbonnel C, Harousseau JL, Attal M, Marit G, Mathiot C, Facon T,
Moreau P, Anderson KC, Campion L, Munshi NC, Minvielle S: Prognostic significance of copy-number alterations in multiple myeloma. J Clin Oncol 2009;27:4585-4590.

20 Kristinsson SY, Pfeiffer RM, Björkholm M, Schulman S, Landgren O: Thrombosis is associated with inferior survival in multiple myeloma. Haematologica 2012;97:1603-1607.

21 Kakkar AK, Macbeth F: Antithrombotic therapy and survival in patients with malignant disease. Br J Cancer 2010;102(suppl 1):S24S29.

22 Altınbaş M, Coskun HS, Er O, Ozkan M, Eser B, Unal A, Cetin M, Soyuer S: A randomized clinical trial of combination chemotherapy with and without low molecular-weight heparin in small cell lung cancer. J Thromb Haemost 2004;2:1266-1271.

23 Klerk CP, Smorenburg SM, Otten HM, Ozkan M, Eser B, Unal A, Cetin M, Soyuer S: The effect of low molecular weight heparin on survival in patients with advanced malignancy. J Clin Oncol 2005;23:2130-2135.

24 Lebeau B, Chastang C, Brechot JM, Capron F, Dautzenberg B, Delaisements C, Mornet M, Brun J, Hurdebourcq JP, Lemarie E: Subcuta- neous heparin treatment increases survival in small cell lung cancer. 'Petites Cellules' Group. Cancer 1994;74:38-45.

25 Morgan GJ, Gregory WM, Davies FE, Bell SE, Szubert AJ, Brown JM, Coy NN, Cook G, Russell NH, Rudin C, Roddie H, Drayson MT, Owen RG, Ross FM, Jackson GH, Child JA; National Cancer Research Institute Haematological Oncology Clinical Studies Group: The role of maintenance thalidomide therapy in multiple myeloma: MRC Myeloma IX results and meta-analysis. Blood 2012;119:715.

26 Bagratuni T, Wu P, Gonzalez de Castro D, Davenport EL, Dickens NJ, Walker BA, Boyd K, Johnson DC, Gregory W, Morgan GJ, Davies $\mathrm{FE}$ : $\mathrm{XBP} 1 \mathrm{~s}$ levels are implicated in the biology and outcome of myeloma mediating different clinical outcomes to thalidomidebased treatments. Blood 2010;116:250-253.

27 Seidel C, Hjorth-Hansen H, Bendz B, Borset M, Sandset PM, Hansen JB, Sundan A, Waage A: Hepatocyte growth factor in serum after injection of unfractionated and low molecular weight heparin in healthy individuals. $\mathrm{Br}$ Haematol 1999;105:641-647. 